American Journal of Agricultural and Biological Sciences 3 (1): 330-336, 2008

ISSN 1557-4989

(C) 2008 Science Publications

\title{
Specific Heat and Thermal Conductivity of Berberis Fruit (Berberis vulgaris)
}

\author{
Mortaza Aghbashlo, Mohammad Hossein Kianmehr and Seyed Reza Hassan-Beygi \\ Department of Agricultural Technical Engineering, Faculty of Agricultural Eng., \\ Abureyhan Campus, University of Tehran, Tehran, Iran
}

\begin{abstract}
Berberis fruit was known as a medicinal and ornamental plant in the world. It is used in medicine to cure the liver, neck and stomach cancer, blood purification and mouth scent. In order to design of equipments and facilities for the drying, preservation and processing of berberis, it is necessary to know about the specific heat and thermal conductivity. Therefore, the objectives of this study were to determine the specific heat and thermal conductivity of berberis as well as to develop mathematical models for estimation of them. The method of mixtures and hot wire as a heating source was used for measuring the specific heat and thermal conductivity of berberis fruit, respectively. The selected variables to simulate variations of berberis thermal properties were moisture content and temperature. The measurements were done at 50,60 and $70^{\circ} \mathrm{C}$ temperature levels and $19.3 \%, 38.5 \%$, $55.4 \%$ and $74.3 \%$ (w.b) moisture content levels. The results show that the specific heat and thermal conductivity of berberis increased linearly from 1.9653 to $3.2811 \mathrm{~kJ} / \mathrm{kg}^{\circ} \mathrm{C}$ and 0.1324 to 0.4898 $\mathrm{W} / \mathrm{m}^{\circ} \mathrm{C}$, respectively with increase in the experimental range of the variables. However, the effect of moisture content on increasing the specific heat and thermal conductivity is more than that of temperature. Regression equations were established which could be used to reasonably estimate the values of the specific heat and thermal conductivity as a function of specified moisture content and temperature.
\end{abstract}

Key words: Berberis fruit, thermal properties, moisture content, temperature

\section{INTRODUCTION}

Berberis fruit (Berberis vulgaris) is known as a medicinal and ornamental plant in the world. The berberis contains organic acids and phenol compounds. The berberis phenol compounds include anthocyanin, carotenoide pigments, phenolase, polyphenolase and glycosidase enzymes ${ }^{[1]}$. Due to the berberis compounds; it is used in medicine to cure the liver, neck and stomach cancer, blood purification and mouth scent. Also, the berberis leaves are used in affections resulting from the lack of Vitamin $\mathrm{C}$, to treat gastric ulcer, treating diarrhea, edema, and treating scurvy ${ }^{[1,2]}$. The freshly ripe berberis is bright-red and egg-shaped in the form of clusters hanging from the branches that gradually change to brown or black color as it loses moisture. Edible seedless berberis fruit is one of the horticultural products that produced in east of Iran in more than 6000 hectares with annual fresh production of 22000 tons, which is mostly supply to the market predominately in dried form ${ }^{[1]}$.
Specific heat and thermal conductivity are used in the engineering design calculations involving thermal processing of agricultural products. In agricultural materials, temperature and moisture content greatly influence the specific heat and thermal conductivity due to the relatively high specific heat and thermal conductivity of water.

Different methods have been used by several researches to determine the specific heat of agricultural and food material. The method of mixtures was used as the most common technique for measuring the specific heat of agricultural products that it reported in the literature $^{[3,4]}$. In this method, the specific heat is determined for the solid by allowing the hot material to be cooled in cold water and equating the heat lost by the substance to the heat gained by the cold water ${ }^{[3,4]}$. The specific heat of spring wheat increased from 1.054 to $2.521 \mathrm{~kJ} / \mathrm{kg}^{\circ} \mathrm{C}$ with temperature in the ranged of $-33.5^{\circ} \mathrm{C}$ to $21.8^{\circ} \mathrm{C}$ and moisture content in the range of $1-23 \%$ dry base ${ }^{[5]}$. Narain et al. ${ }^{[6]}$ and Sreenarayanan and Chattopadhyay ${ }^{[7]}$ determined the specific heat of rice bran in the moisture and temperature ranges of 4.3-

Corresponding Author: $\quad$ M.H. Kianmehr, Department of Agricultural Technical Engineering, Faculty of Agricultural Eng., Abureyhan Campus, University of Tehran, Tehran, Iran. Tel: +98-292-3021043, Fax: +98-2923020340 
$18 \%$ and $38-63^{\circ} \mathrm{C}$, respectively. The specific heat of cumin seed increased with increase in temperature from -70 to $50^{\circ} \mathrm{C}$ and moisture content from $1.8-20.5 \%$ (d.b) ${ }^{[8]}$. The specific heat of shea-nut kernel as a function of moisture content and temperature was determined by Aviara and Haque ${ }^{[9]}$. The specific heat of minor millet grains and flours increased from 1.33 to $2.40 \mathrm{~kJ} / \mathrm{kg}^{\circ} \mathrm{C}$ with moisture content in the range of 10 $30 \%$ (w.b) ${ }^{[10]}$. The specific heat of four varieties of Iranian pistachio nuts as affected by moisture content and temperature was studied by Razavi and Taghizadeh $^{[11]}$.

Transient heat flow method using line heat source was used by many researchers for the determination of thermal conductivity of agricultural materials. In the method using the line heat source, the measurement of temperature at different time interval helps in determination of the thermal conductivity. The thermal conductivity of spring wheat was measured by Chandra and Muir ${ }^{[12]}$ in the moisture range of $4.4-25.5 \%$ and the temperature range of -6 to $20^{\circ} \mathrm{C}$. The thermal conductivity of the gram increased from 0.144 to 0.247 $\mathrm{W} / \mathrm{m}^{\circ} \mathrm{C}$ with moisture and temperature increase in the ranges of $11.5-27.2 \%$ and $10-25^{\circ} \mathrm{C}$, respectively ${ }^{[13]}$. The thermal conductivity of mushrooms was determined in the range of $0.2084-0.5309 \mathrm{~W} / \mathrm{m}^{\circ} \mathrm{C}^{[14]}$. The thermal conductivity of cumin seed increased with the increase in temperature from -50 to $50^{\circ} \mathrm{C}$ and moisture content from $1.8-20.5 \%$ (d.b) ${ }^{[8]}$. The thermal conductivity of shea-nut kernel was determined by Aviara and Haque ${ }^{[9]}$ in the moisture and temperature ranges of 3.32-20.7\% (d.b) and 347.5-349.5 K, respectively. The thermal conductivity of minor millet grains and flours increased from 0.026 to $0.223 \mathrm{~W} / \mathrm{m}^{\circ} \mathrm{C}$ with moisture content in the range of $10-30 \%$ (w.b) and the thermal conductivity of flour was considerably less than that of grains ${ }^{[10]}$.

In order to design of equipments and facilities for the drying, preservation and processing of berberis fruit for making industrial products such as beverages, sauce, jelly, candy, pastilles and colored edible powder as well dried form berberis, it is necessary to know about the specific heat and thermal conductivity. To knowledge of the authors, there is not published information concerning specific heat and thermal conductivity of berberis fruit. Therefore, the objectives of this study were to determine the specific heat and thermal conductivity of berberis as well as to develop mathematical models for prediction of the specific heat and thermal conductivity of berberis as a function of moisture content and temperature.

\section{MATERIALS AND METHODS}

Freshly harvested berberis fruit were purchased from a local farm of Birjand city of Khorasan province, East of Iran. The samples were kept in refrigerator at about $5^{\circ} \mathrm{C}$ until experiments performed. The unripe, immature and burst berberis fruit were separated manually. Moisture content of the fresh berberis was determined by hot air oven method ${ }^{[15]}$. About $20 \mathrm{~g}$ sample was placed in a pre-weighed box and was weighed again accurately to give the exact weight of sample. It was kept in hot air oven maintained at $105 \pm 2^{\circ} \mathrm{C}$ until the variations between two weighing intervals mass were within $0.05 \mathrm{~g}$. Amount of sample moisture evaporated was calculated and moisture content $\left(\mathrm{M}_{\mathrm{C}}\right)$ was expressed as \% w.b (wet basis). The described method was adopted for all $\mathrm{M}_{\mathrm{C}}$ determinations using four replicates to get an average value of $\mathrm{M}_{\mathrm{C}}$ for any sample. The fresh berberis used in this investigation had $74.3 \%$ (w.b) initial moisture content.

The selected variables to simulate variations of berberis thermal properties as affected by the actual process conditions to be used during the dehydration were moisture content and temperature. The range of the variables is shown in tables 1. Each test was replicated three times and average values are reported.

Table 1: Matrix of the experimentation

\begin{tabular}{ccccc}
\hline Parameters & \multicolumn{4}{c}{ Levels of Parameters } \\
& 1 & 2 & 3 & 4 \\
\hline Temperature $\left({ }^{\circ} \mathrm{C}\right)$ & 50 & 60 & 70 & - \\
Moisture content (w.b.\%) & 19.3 & 38.5 & 55.4 & 74.3 \\
\hline
\end{tabular}

Specific heat determination: In this research work, the method of mixtures was used for measuring the specific heat of berberis. The following assumptions could be considered for using this technique: (1) heat loss during transfer of capsule from the hot air oven to the calorimeter was negligible. (2) At the end of heating, temperature of capsule and berberis fruit was equal. (3) Evaporation loss in the calorimeter during equilibration period was negligible. (4) Changes in the heat capacities of the calorimeter and the capsule within the range of studied temperature were not significant.

An experimental set-up was similar to the one used by previous researchers ${ }^{[7,10,11,14]}$. The apparatus consisted of cylindrical aluminum capsules for holding the samples with $15.2 \mathrm{~mm}$ diameter, $52.6 \mathrm{~mm}$ height and $2.1 \mathrm{~mm}$ wall thickness which were provided with a threaded lid to ensure no moisture was lost from the sample and no water entered into the capsule during the 
experiment, T-type thermocouples with a temperature indicator, $250 \mathrm{~cm}^{3}$ capacity insulated vacuum thermoflasks and a hot air oven.

The heat capacity of the calorimeter was determined experimentally. For this purpose a known quantity of distilled water at a known high temperature (maximum $70^{\circ} \mathrm{C}$ ) was added to calorimeter that containing a known quantity of distilled water at a known low temperature. The system was assumed to be adiabatic. Therefore, the heat capacity of the calorimeter was determined by following equation [11,14].

$$
H_{f}=\frac{M_{c w} C_{w}\left(T_{e}-T_{c w}\right)-M_{h w} C_{w}\left(T_{h w}-T_{e}\right)}{\left(T_{h w}-T_{e}\right)}
$$

Where:

$\mathrm{H}_{\mathrm{f}}=$ Heat capacity of flask $\left(\mathrm{cal} /{ }^{\circ} \mathrm{C}\right)$,

$\mathrm{M}_{\mathrm{cw}}=$ Mass of cold water ( $\mathrm{g}$ ),

$\mathrm{M}_{\mathrm{hw}}=$ Mass of hot water (g),

$\mathrm{C}_{\mathrm{w}}=$ Specific heat of water $\left(1 \mathrm{cal} / \mathrm{g}^{\circ} \mathrm{C}\right)$,

$\mathrm{T}_{\mathrm{cw}}=$ Temperature of cold water $\left({ }^{\circ} \mathrm{C}\right)$,

$\mathrm{T}_{\mathrm{hw}}=$ Temperature of hot water $\left({ }^{\circ} \mathrm{C}\right)$, and

$\mathrm{T}_{\mathrm{e}}=$ Temperature of equilibrium cold water $\left({ }^{\circ} \mathrm{C}\right)$.

The heat capacity of cylindrical aluminum test capsule was also determined experimentally. For this purpose the capsule at a known high temperature was added to the calorimeter that containing a known quantity of distilled water at a known low temperature (room temperature). The system was assumed to be adiabatic. Therefore, the heat capacity of the capsule was given by equation $(2)^{[11,14]}$ :

$H_{c}=\frac{\left(H_{f}+M_{c w} C_{w}\right)\left(T_{e}-T_{c w}\right)}{\left(T_{c}-T_{e}\right)}$

Where:

$\mathrm{H}_{\mathrm{c}}=$ Heat capacity of capsule $\left(\mathrm{cal} /{ }^{\circ} \mathrm{C}\right)$, and

$\mathrm{T}_{\mathrm{c}}=$ Temperature of capsule $\left({ }^{\circ} \mathrm{C}\right)$.

To determine the specific heat of the berberis, the test capsule was filled with the berberis and was maintained into hot air oven at desired temperature for at least one hour. Then the filled capsule was dropped into the calorimeter, which containing a known quantity of distilled water at a known low temperature and equilibrium temperature was recorded. The specific heat of berberis was calculated using the following heat balance equation ${ }^{[11,14]}$ :

$C_{p}=\frac{\left(H_{f}+M_{c w} C_{w}\right)\left(T_{e}-T_{c w}\right)-H_{c}\left(T_{m}-T_{e}\right)}{M_{m}\left(T_{m}-T_{e}\right)} \times 4.1868$

Where:

$\mathrm{C}_{\mathrm{p}}=$ Specific heat of berberis $\left(\mathrm{kJ} / \mathrm{kg}^{\circ} \mathrm{C}\right)$,

$\mathrm{M}_{\mathrm{m}}=$ Mass of berberis $(\mathrm{g})$, and

$\mathrm{T}_{\mathrm{m}}=$ Temperature of berberis $\left({ }^{\circ} \mathrm{C}\right)$.
Thermal conductivity determination: To measure the thermal conductivity of berberis the transient-state heat transfer methods was used in this study. The thermal conductivity was determined based on the relationship between the sample core temperature and the heating time. A bare wire was used as a heating source. For an infinitely long line heater in an infinite, homogeneous and isotropic medium, the temperature rise at a radial distance, $r$, from the line heat source can be represented by the following equation ${ }^{[16]}$ :

$T-T_{o}=-\left(\frac{Q}{4 \pi k}\right) E i\left(-\frac{r^{2}}{4 \alpha t}\right)$

Where:

$\mathrm{Q}=$ The heat production of the line heat source $(\mathrm{W})$,

$\mathrm{K}=$ The thermal conductivity $\left(\mathrm{W} / \mathrm{m}^{\circ} \mathrm{C}\right)$,

$\mathrm{A}=$ The thermal diffusivity $\left(\mathrm{m}^{2} / \mathrm{s}\right)$,

$\mathrm{T}=$ The time (s), and

$\operatorname{Ei}(-x)=$ An exponential integral function.

The equation (4) can be restated as:

$T-T_{o}=\left(\frac{Q}{4 \pi k}\right)\left\{\ln \frac{4 \alpha t}{r^{2}}-\gamma+\left(\frac{r^{2}}{4 \alpha t}\right)-\frac{(-1)^{2}}{2.2 !}\left(\frac{r^{2}}{4 \alpha t}\right)^{2} \cdots \frac{(-1)^{n}}{n \cdot n !}\left(\frac{r^{2}}{4 \alpha t}\right)^{n}\right\}$

Where $\gamma$ is Euler's constant. For small values of $r^{2} /(4 \alpha t)$, all terms after the second one at the righthand side of the equation (5) would be negligible. Thus, the equation (5) can be expressed as:

$T-T_{o}=\left(\frac{Q}{4 \pi k}\right)\left\{\ln \left(\frac{4 \alpha e^{-\gamma}}{r^{2}}\right)+\ln t\right\}$

Eq. (6) means that the gradient of a plot of $(\Delta T)$ versus natural logarithm of time $(\operatorname{Ln}(\mathrm{t}))$ is equal to $S=Q /(4 \pi k)$. The thermal conductivity can then be calculated as:

$k=\frac{Q \Delta \operatorname{Ln}(t)}{4 \pi \Delta T}$

or

$k=\frac{Q}{4 \pi S}$

Since $Q=I^{2} R$, the above equation can be rearranged as:

$k=\frac{I^{2} R}{4 \pi S}$

Where:

$\mathrm{I}=$ The electric current $(\mathrm{A})$, and

$\mathrm{R}=$ The electric resistance per unit length $\left(\Omega \mathrm{m}^{-1}\right)$.

A hot-wire thermal conductivity apparatus used in this study is shown in Fig. 1. The apparatus consisted of a brass cylindrical sample tube $240 \mathrm{~mm}$ in height and $58.6 \mathrm{~mm}$ in inner diameter, with a removable rubber top cover and fixed bottom base. A constantan resistance heating wire with a diameter of $0.32 \mathrm{~mm}$ and length of 
$235 \mathrm{~mm}(11.49 \Omega)$ was connected to constant DC power source and the desired current adjusted by resistor. A pre-calibrated $0.8 \mathrm{~mm}$ diameter T-type thermocouple were installed for measuring the core temperature and glued approximately $1 \mathrm{~mm}$ from heating wire at the middle of the heating wire. The assumption of an infinite medium required that the surface temperature of the sample holder was constant during the experiments. To validate this assumption, a second thermocouple was attached to the outer surface of the cylinder to monitor its temperature. A data logger multi-type thermometer (CHY502A, Taiwan) was used to collect the temperature data. The berberis filled in the sample container were placed in an oven which was maintained at a pre-set initial temperature (Table 1), for at least $2 \mathrm{~h}$, in order for the samples and the container to equilibrate to the desired initial temperature. As soon as a constant temperature of the thermocouples was reached, a constant DC voltage was applied from the power supplier, resulting in a constant electric current through the heating wire. A digital multi-meter was used to monitor the current. Power levels of 2.5-6 $\mathrm{Wm}^{-1}$ were used, which resulted in a temperature rise of the sample of 5 to $14^{\circ} \mathrm{C}$ at the thermocouple tip. The thermocouple temperatures were recorded by the data logger every second for $3 \mathrm{~min}$. The recorded temperature values were then plotted against the natural logarithm of elapsed time. The slope (S) and the coefficient of determination $\left(\mathrm{R}^{2}\right)$ were determined successively for each experimental run using different data intervals. The slope for the highest $R^{2}$ was selected from the data intervals and used in the thermal conductivity determination ${ }^{[18,19]}$. Slopes with $\mathrm{R}^{2}$ values of less than 0.990 were not used in the thermal conductivity determination. The thermal conductivity was calculated using the equation (9). The thermal conductivity measurements were conducted at temperatures and moisture contents were shown in table 1.

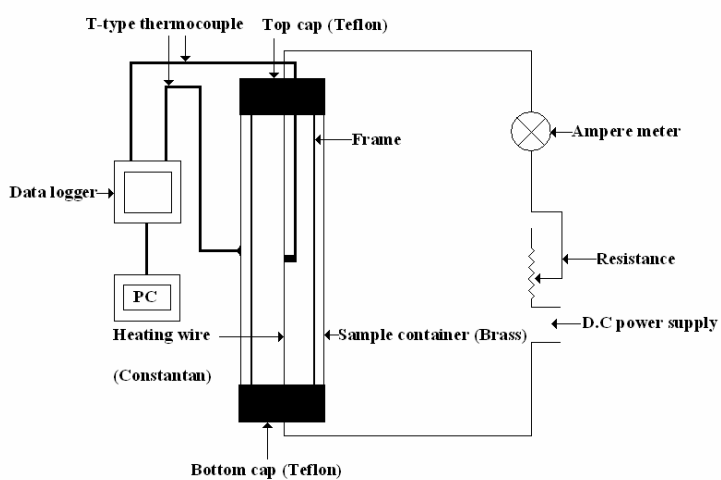

Fig 1: Schematic of the apparatus used for measuring thermal conductivity of berberis; PC, personal computer; DC, direct current

\section{RESULTS AND DISCUSSION}

The specific heat: The variations in specific heat of berberis with moisture content and temperature are presented in Fig. 2. The specific heat of berberis was varied from a minimum of $1.9653 \mathrm{~kJ} / \mathrm{kg}^{\circ} \mathrm{C}$ to maximum of $3.2811 \mathrm{~kJ} / \mathrm{kg}^{\circ} \mathrm{C}$ for the experimental range of the variables. As depicted from Fig. 2, an increasing trend in the specific heat of berberis was observed with the increase in both moisture content and temperature. Multiple regression analysis showed that there is a linear relationship between dependent variable of the specific heat $\left(\mathrm{C}_{\mathrm{p}}\right)$ and the independent variables of moisture content $\left(\mathrm{M}_{\mathrm{C}}\right)$ and temperature $(\mathrm{T})$ as follows:

$C_{p}=1.00802+0.01897 M_{c}+0.001188 T \quad\left(\mathrm{R}^{2}=0.9939\right)$

The above estimation equation was a first order linear model, so the response surface shown in Fig. 2 is also flat. To evaluate the individual effect of independent variables on the specific heat, analysis of variance (ANOVA) table was constructed as shown in table 2. It is obviously that the high F-value of regression confirmed the adequacy of the linear fitted model which accounted for $99.39 \%$ variation of the specific heat with in the experimental range of input variables studied ${ }^{[20]}$. Also, comparison between the measured and estimated values of specific heat (Fig.3) showed that the maximum differences between them were within $\pm 0.05 \mathrm{~kJ} / \mathrm{kg}^{\circ} \mathrm{C}$, which is desirable accuracy for estimating the specific heat. Comparing F-values of the moisture content and temperature showed that the effect of moisture content on the specific heat was higher (high F-value) than the effect of temperature (low F-value). The behavior of response surface in Fig.2 also confirmed this inference.

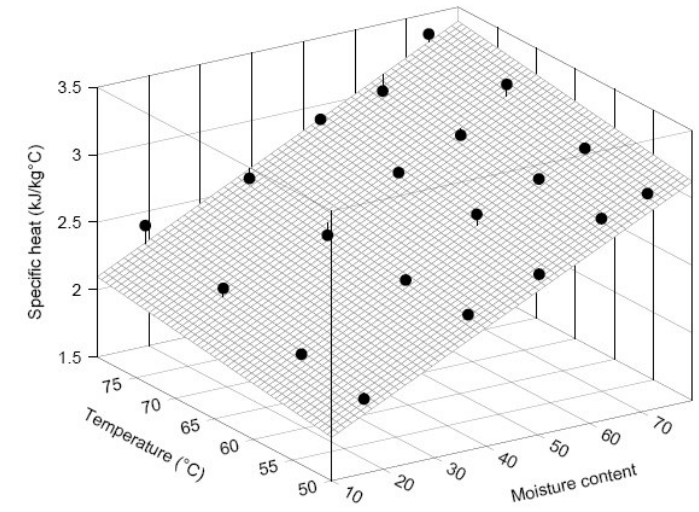

Fig. 2: Effect of temperature and moisture content on specific heat of berberis 
Table 2: Analysis of variance (ANOVA) for effect of moisture content and temperature on specific heat and thermal conductivity of berberis

\begin{tabular}{|c|c|c|c|c|c|}
\hline $\begin{array}{l}\text { Source of } \\
\text { variation }\end{array}$ & $\begin{array}{l}\text { Sum of } \\
\text { squares }\end{array}$ & $\begin{array}{l}\mathrm{D} \\
\mathrm{F}\end{array}$ & $\begin{array}{l}\text { Mean } \\
\text { sum of } \\
\text { squares }\end{array}$ & $\mathrm{F}_{\mathrm{cal}}$-value & Prob. \\
\hline \multicolumn{6}{|l|}{ Specific heat } \\
\hline Regression & 1.8970 & 2 & 0.9485 & $734.957^{* * * *}$ & 0.0000 \\
\hline $\mathrm{M}_{\mathrm{C}}$ & 1.7840 & 1 & 1.7840 & $1382.370^{* * * *}$ & 0.0000 \\
\hline $\mathrm{T}$ & 0.1130 & 1 & 0.1130 & $87.544^{* * *}$ & 0.0000 \\
\hline Residual & 0.0116 & 9 & 0.0013 & & \\
\hline Total & 1.9086 & 11 & & & \\
\hline \multicolumn{6}{|l|}{$\begin{array}{l}\text { Thermal } \\
\text { conductivity }\end{array}$} \\
\hline Regression & 0.1683 & 2 & 0.0842 & $698.502^{* * *}$ & 0.0000 \\
\hline $\mathrm{M}_{\mathrm{C}}$ & 0.1637 & 1 & 0.1637 & $1358.784^{* * * *}$ & 0.0000 \\
\hline $\mathrm{T}$ & 0.0046 & 1 & 0.0046 & $38.220^{* * *}$ & 0.0002 \\
\hline Residual & 0.0011 & 9 & 0.0001 & & \\
\hline Total & 0.1694 & 11 & & & \\
\hline
\end{tabular}

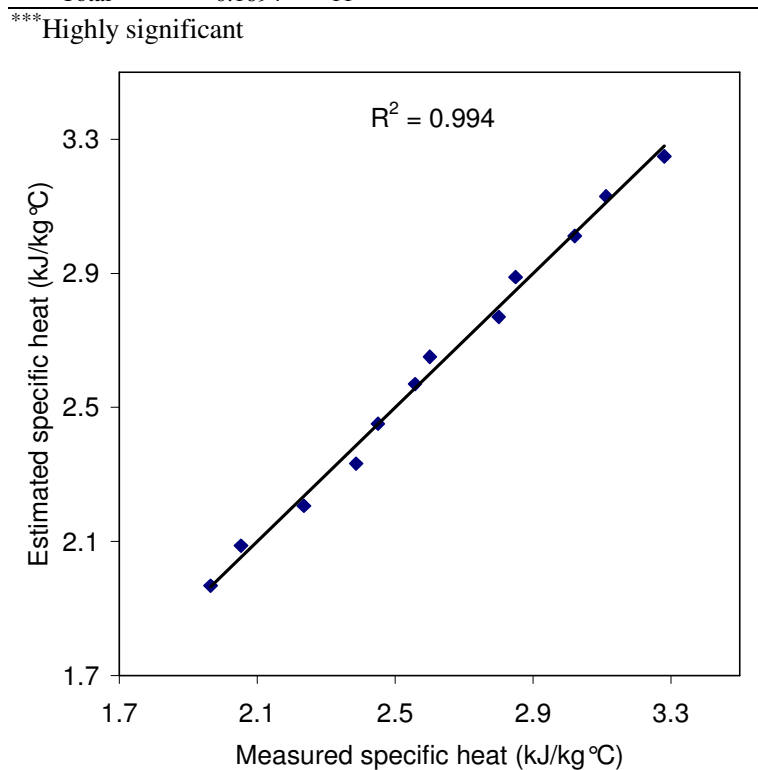

Fig. 3: Estimated specific heat of berberis versus measured values

The increasing trend of the specific heat of berberis with increase in moisture content and temperature is in agreement with findings of some pervious researchers. The specific heat of hard red spring wheat increased linearly from 1.054 to $2.521 \mathrm{~kJ} / \mathrm{kg}^{\circ} \mathrm{C}$ with temperature in the range of $-33.5^{\circ} \mathrm{C}$ to $21.8^{\circ} \mathrm{C}$ and moisture content in the range of $1-23 \%$ dry base ${ }^{[5]}$. Investigations of Narain et al., ${ }^{[6]}$ and Sreenarayanan and Chattopadhyay ${ }^{[7]}$ revealed that the specific heat of rice bran, a powdery material, were increased linearly from 1.702 to $2.189 \mathrm{~kJ} / \mathrm{kg}^{\circ} \mathrm{C}$ in the moisture and temperature ranges of $4.3-18 \%$ and $38-63^{\circ} \mathrm{C}$, respectively. The specific heat of Cassava, Yam and Plantain was reported by Njie et al., ${ }^{[21]}$ as a function of moisture content and temperature. They found that there was similarity in the specific heat of three crops and the specific heat of the crops increased with moisture content and temperature. Shrivastava and Datta ${ }^{[14]}$ studies showed that the specific heat of mushrooms increased linearly from 1.7158 to $3.9498 \mathrm{~kJ} / \mathrm{kg}^{\circ} \mathrm{C}$ with increase in temperature and moisture content in the range of $40-70^{\circ} \mathrm{C}$ and $10.24-89.68 \%$ w.b, respectively. Singh and Goswami ${ }^{[8]}$ investigations revealed that the specific heat of cumin seed was dependent to both moisture and temperature and increased as a secondorder polynomial from 1.330 to $3.090 \mathrm{~kJ} / \mathrm{kg}^{\circ} \mathrm{C}$ with temperature and moisture content in the ranges of -70 to $50^{\circ} \mathrm{C}$ and $1.8-20.5 \%$ d.b, respectively except that of $20.5 \%$ at which it displayed a linear relationship. The specific heat of shea-nut kernel as a function of moisture content and temperature was determined by Aviara and Haque ${ }^{[9]}$. They found that the specific heat of shea-nut kernel was both moisture and temperature dependent in the ranges of $3.32-20.7 \%$ (d.b) and 30$93^{\circ} \mathrm{C}$, respectively and increased linearly from 1.792 to $3.172 \mathrm{~kJ} / \mathrm{kg}^{\circ} \mathrm{C}$. As well, Razavi and Taghizadeh ${ }^{[11]}$ research work showed that the specific heat of four varieties of Iranian pistachio nuts was a function of moisture content and temperature. They found that the specific heat increased from 0.419 to $2.930 \mathrm{~kJ} / \mathrm{kg}^{\circ} \mathrm{C}$ with increasing moisture content from 5 to $45 \%$ w.b. and temperature from 25 to $70^{\circ} \mathrm{C}$ as a non-linear polynomial.

The thermal conductivity: The thermal conductivity of berberis varied from a minimum of $0.1324 \mathrm{~W} / \mathrm{m}^{\circ} \mathrm{C}$ to maximum of $0.4898 \mathrm{~W} / \mathrm{m}^{\circ} \mathrm{C}$ depending upon the moisture content and temperature within the experimental range of the variables. An increasing trend in the thermal conductivity of berberis was also observed with the increase in both moisture content and temperature (Fig.4). Multiple regression analysis showed that there is also a linear relationship between the thermal conductivity $(\mathrm{k})$ and the moisture content $\left(\mathrm{M}_{\mathrm{C}}\right)$ and temperature $(\mathrm{T})$ of berberis as follows:

$k=-0.10065+0.00574 M_{c}+0.00239 T \quad\left(\mathrm{R}^{2}=0.9934\right) \quad(11)$

The response surface presented in Fig. 4 is almost flat due to the linear model fitted. The analysis of variance table (table 2) clearly indicates the greater effect of the moisture content (high F-value) than that of the temperature on the thermal conductivity. The magnitudes of respective regression coefficients in equation (11) also confirmed this result. The model seems adequately fitted based on the observation of high F-value as well as high coefficient of determination $\left(\mathrm{R}^{2}\right)$. The model accounted for $99.34 \%$ variation in the thermal conductivity within the experimental range of input variables studied ${ }^{[20]}$. 
Comparing the measured and estimated values of the thermal conductivity (Fig. 5) showed that the maximum differences between them were within $\pm 0.02 \mathrm{~W} / \mathrm{m}^{\circ} \mathrm{C}$, which is desirable accuracy for estimating the thermal conductivity.

Figure 4 revealed that the thermal conductivity of berberis also increased with increase in moisture content and temperature, which is in general agreement with findings of some previous researchers. Investigations of Chandra and Muir ${ }^{[12]}$ showed that the thermal conductivity of hard red spring wheat increased from 0.1382 to $0.167 \mathrm{~W} / \mathrm{m}^{\circ} \mathrm{C}$ in the moisture range of $4.4-25.5 \%$ and the temperature range of -6 to $20^{\circ} \mathrm{C}$. Dutta et al., ${ }^{[13]}$ research works showed that the thermal conductivity of the gram increased linearly from 0.144 to $0.247 \mathrm{~W} / \mathrm{m}^{\circ} \mathrm{C}$ with moisture and temperature increase in the ranges of $11.5-27.2 \%$ and $10-25^{\circ} \mathrm{C}$, respectively. Shrivastava and Datta ${ }^{[14]}$ investigations showed that the thermal conductivity of mushrooms increased from 0.2084 to $0.5309 \mathrm{~W} / \mathrm{m}^{\circ} \mathrm{C}$ with increase in temperature and moisture content in the ranges of 40$70^{\circ} \mathrm{C}$ and $10.24-89.68 \%$ w.b., respectively. The thermal conductivity of cumin seed increased from 0.046 to $0.223 \mathrm{~W} / \mathrm{m}^{\circ} \mathrm{C}$ with increase in temperature from -50 to $50^{\circ} \mathrm{C}$ and moisture content from 1.8 to $20.5 \%$ d.b and its variation with temperature and moisture content was best represented by second order polynomial ${ }^{[8]}$. Aviara and Haque ${ }^{[9]}$ found that the thermal conductivity of ground shea-nut kernel increased linearly with increase in moisture content in the range of $3.32-20.7 \%$ (d.b.) and temperature range within 347.5-349.5 K. Yang et al., ${ }^{[17]}$ studies revealed that the thermal conductivity of rough rice increased from 0.080 to $0.138 \mathrm{~W} / \mathrm{m}^{\circ} \mathrm{C}$ in the temperature range of $3-69^{\circ} \mathrm{C}$ and moisture content range of $9.2-17.0 \%$ w.b. A second order polynomial was developed to estimate the values of thermal conductivity as a function of moisture content and temperature by these researchers. Njie et al., ${ }^{[21]}$ investigations showed that the thermal conductivity of Cassava, Yam and Plantain was a function of moisture content and temperature. Also, they found that the thermal conductivity of the three crops increased with moisture content and temperature.

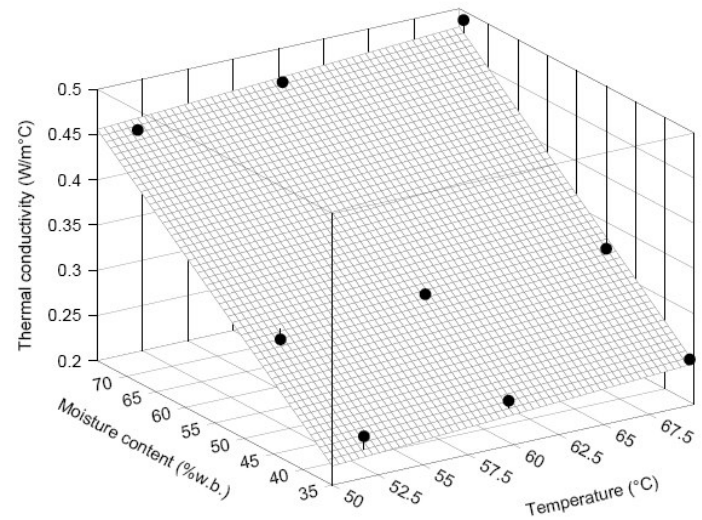

Fig. 4: Effect of temperature and moisture content on thermal conductivity of berberis

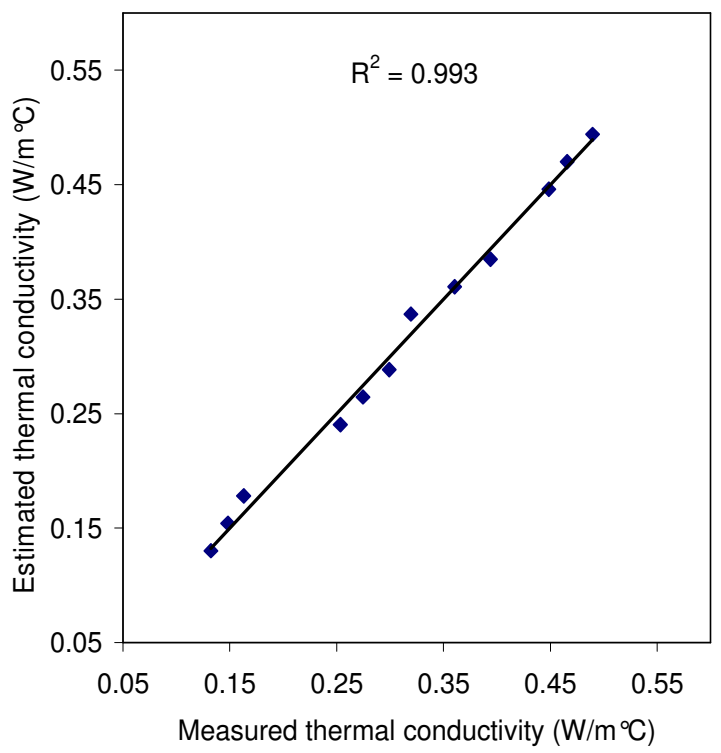

Fig. 5: Estimated thermal conductivity of berberis versus measured values

\section{CONCLUSION}

The specific heat and thermal conductivity of berberis fruit studied are greatly influenced by moisture content and temperature. The results clearly showed that there is a strong linear correlation between the specific heat and thermal conductivity of berberis with moisture content and temperature. The specific heat and thermal conductivity increased from 1.9653 to 3.2811 $\mathrm{kJ} / \mathrm{kg}^{\circ} \mathrm{C}$ and 0.1324 to $0.4898 \mathrm{~W} / \mathrm{m}^{\circ} \mathrm{C}$, respectively within the range of input variables studied. The effect of the moisture content on increasing the specific heat and thermal conductivity were more than that of temperature. The developed models could be used to estimate the thermal properties of berberis accurately so the maximum differences between the measured and estimated values of specific heat and thermal conductivity were within $\pm 0.05 \mathrm{~kJ} / \mathrm{kg}^{\circ} \mathrm{C}$ and \pm 0.02 $\mathrm{W} / \mathrm{m}^{\circ} \mathrm{C}$, respectively.

\section{ACKNOWLEDGMENT}

The authors would like to acknowledge University of Tehran for providing support of this research.

\section{REFERENCES}

1. Kafi, M. and A. Balandari, 2002. Berberis production and processing. 1st Edn. Mashhad, Ferdowsi University Publication (in Persian). 
2. Duke, J.A., 1991. Handbook of medicinal herbs. 8th Edn. Florida, CRC Press, Inc.

3. Mohsenin, N.N. 1980. Thermal properties of foods and agricultural materials. 1st Edn. New York, Gordon and Breach.

4. Tabil, L. G., 1999. Specific Heat of Agricultural and Food Materials. Research report, Department of Agricultural and Bioresource Engineering, University of Saskatchewan, Canada.

5. Muir, W. E. and E. Viravanichai, 1972. Specific Heat of Wheat. J. Agric. Eng. Res., 17: 338-342.

6. Narain, M., S.S.C. Bose, M. Jha and V.K. Dwivedi, 1978. Physicothermal Properties of Rice Bran. J. Food Sci. and Tec., 15 (1): 18-19.

7. Sreenarayanan, V.V. and P.K. Chattopadhyay, 1986. Specific Heat of Rice Bran. Agric. Wastes, 16: 217-224.

8. Singh, K.K. and T.K. Goswami, 2000. Thermal Properties of Cumin Seed. J. Food Eng., 45:181187.

9. Aviara, N.A. and M.A. Haque, 2001. Moisture Dependence of Thermal Properties of Shea-nut Kernel. J. Food Eng., 47:109-113.

10. Subramanian, s. and R. Viswanathan. 2003. Thermal Properties of Minor Millet Grains and Flours. Biosystems Eng., 84 (3): 289-296.

11. Razavi, S.M.A. and M. Taghizadeh, 2007. The Specific Heat of Pistachio Nuts as Affected by Moisture Content, Temperature, and Variety. J. Food Eng., 79: 158-167.

12. Chandra, S. and W.E. Muir, 1971. Thermal Conductivity of Spring Wheat at Low Temperatures. Trans. ASAE, 14 (4): 644-648.

13. Dutta, S.K., V.K., Nema and R.K. Bhardwaj, 1988. Thermal Properties of Gram. J. Agric. Eng. Research, 39: 269-275.
14. Shrivastava, M. and A.K. Datta, 1999. Determination of Specific Heat and Thermal Conductivity of Mushrooms (Pleurotus Forida). J. Food Eng., 39: 255-260.

15. AOCC Approved Methods. 1976. Moisture Determination, Vol. 44-15A. Association of Cereal Chemists.

16. Van der Held, E.F.M. and F.G. Van Drunen, 1949. A Method of Measuring the Thermal Conductivity of Liquids. Physica, 15: 865-881.

17. Yang, W., T.J. Siebenmorgen, T.P.H. Thielen and A.G. Cnossen, 2003. Effect of Glass Transition on Thermal Conductivity of Rough Rice. Biosystem Eng., 84 (2): 193-200.

18. Murakami, E.G. and M.R. Okos, 1988. Measurement and Prediction of Thermal Properties of Foods. In Food Properties and Computer-aided Engineering of Food Processing Systems, eds. P.R. Singh and A.G. Medina, 3-48. Boston, MA: Kluwer Academic Publishers.

19. Casada, M.E. and L.R. Walton, 1989. Thermal Conductivity of Baled Burley Tobacco. Trans. ASAE, 32 (2): 977-982.

20. Gomez, K. and A.A. Gomez, 1984. Statistical procedures for agricultural research. 2nd Edn. New York, Wiley Inc.

21. Njie, D.N., T.R. Rumsey and R.P. Singh, 1998. Thermal Properties of Cassava, Yam and Plantain. J. Food Eng., 37: 63-76. 